\title{
DIGITAL TRANSFORMATION OF EDUCATION: ENVISIONING POST-COVID EDUCATION IN LATVIA
}

\author{
Zanda Rubene, Linda Daniela, Edīte Sarva, Arta Rūdolfa \\ University of Latvia, Latvia
}

\begin{abstract}
The project "Life with COVID-19: Evaluation of overcoming the coronavirus crisis in Latvia and recommendations for societal resilience in the future" (CoLife) was launched in Latvia in the summer of 2020. In this project, researchers representing different fields of social sciences were involved; researchers of education sciences were aiming to find out how the COVID-19 crisis contributed to the digital transformation of education and which changes in education caused by the COVID-19 crisis situation should be maintained in the future. The results of the project are a scientific prognosis on future action scenarios related to the digital transformation of education in Latvia, scientifically backed recommendations for related competency transformation, and tools for evaluating proposed solutions from the perspective of education to conceptualize recommendations for policy-makers on the digital transformation of education in relation to the digitalization and use of digital solutions at all levels of education (preschool, general education, higher education), thus laying the foundation for establishing and implementing a flexible and student-focused education. This article is dedicated to conceptualizing the recommendations for policy-makers on the digital transformation of education using the Delphi method.
\end{abstract}

Keywords: COVID-19, digital learning platforms, digital transformation of education, (pedagogical) digital competence of educators, remote learning,

\section{Introduction}

Experts from the World Health Organization say that "the virus is here to stay and will be a constant threat for the foreseeable future" (Nabarro \& Atkinson, 2020). This is a reminder that the public needs to learn to live with COVID-19 until the vaccines have been sufficiently developed and rolled out internationally to allow the lifting of restrictions and treatments are developed. Addressing the challenges of the virus is not just a matter for the medical sciences - it poses challenges for all academic fields, including the social sciences and, especially, the educational sciences, as 
the crisis caused by the virus has changed education around the world in a very short time.

Therefore, the project "Life with COVID-19: Evaluation of overcoming the coronavirus crisis in Latvia and recommendations for societal resilience in the future" (CoLife) was launched in Latvia in the summer of 2020. The project was implemented by Latvian social scientists and is based on the recognition that this new situation also requires new ways of researching society and analyzing socio-political processes. That is why a novel model of cooperation was created, in which scientists from different institutions and different fields form scientific groups that share a common vision on finding a suitable approach to the changed social situation. This is a social science project with a public focus; representatives of different social groups are directly involved in the development of the study itself - their opinions, experience, and behavior are analyzed in interviews, focus groups, surveys, and behavioral observations.

The results of the CoLife study - recommendations for policy development for various institutions - will be applied by local, regional, and state institutions and non-governmental organizations to improve public resilience to future crisis situations. Thus, the findings and recommendations of the study will be available for policy-makers, institutions, and civil society, as well as for individuals looking for the optimal way to live with the consequences caused by the COVID-19 crisis in the long run.

In the field of education sciences, the task of the project was to collaborate with experts in the field of computer science to develop a scientific prognosis on future action scenarios, scientifically backed recommendations for the digital transformation of education, and to provide tools for the evaluation of the proposed solutions. The findings of this study will help scientists as well as policy-makers and government authorities to develop efficient communication plans and reach broader audiences.

Finally, we will scrutinize the effects of the abrupt and radical shift to remote learning during the state of emergency in Latvia. This shift was an unprecedented event both in Latvia and globally, and we plan ample opportunities to interact with the international scholarly community to study this phenomenon and share our data and findings. The novelty of the research is based on its orientation towards the creation of new guidelines and recommendations for policy-makers of all levels in Latvia (including regional, institutional, and state level) related to the digital transformation of education. 


\section{Digital transformation of education in the context of the COVID-19 crisis}

Digital transformation, i. e. "a process that aims to improve an entity by triggering significant changes to its properties through combinations of information, computing, communication, and connectivity technologies" (Vial, 2019), is taking place in all spheres of our lives. The field of education has been somewhat resistant to widespread digital transformation up until the crisis caused by COVID-19 for various reasons - a lack of financing for technologies and technological solutions; a lack of continuous technological support and quality further education for educators; a negative attitude towards technologies caused by a lack of experience or negative experience using technologies; concerns about increased screen time for students and its consequences; concerns about technology companies' possible impact on the curriculum and education policy; and last but not least the need to shift the focus on student-centered education since remote learning reduces the amount of control that teachers have over students and their learning process and increases students' responsibility for their learning, thus demanding a new approach to teaching (Azorín 2020, Dhawan 2020, Reimer, Schleiche 2020, Digiuseppe et al. 2017, Bonde et al. 2014.).

The COVID-19 crisis overshadowed all of these reasons with an unprecedented and unavoidable need for long-term mass remote learning. This need could not be fully met by any other means than using technologies, therefore considerably accelerating the digital transformation of education by investing a large amount of resources in it - not only by buying the technologies and technological solutions needed to carry out remote learning but also by organizing learning events for educators, students, and their parents and by searching for new approaches to enhance students' remote learning experience. We acknowledge that the digital transformation of education in these circumstances is somewhat unusual as it is not strategically initiated or led, but rather is a desperate attempt to adjust to the state of current affairs (Azorín 2020, Iivari et al. 2020, Karalis 2020, Tria 2020). Nevertheless, solutions for providing continued access to education relied extensively on digital technologies and initiated attempts to manage and deal with a variety of structural and cultural changes and barriers obstructing the successful implementation of digital solutions in education (Darling-Hammond, Hyler 2020, Harris 2020, Reimer, Schleiche 2020).

The COVID-19-caused crisis will pass, and it is clear that long-term remote learning has risks, especially for younger students, students lacking the motivation or skills to direct their own learning, students with learning difficulties, and students from socially disadvantaged families (Bundell et al. 2020, Reimer, Schleiche 2020, Dhawan 2020, Daniela, Rubene, 
Rudolfa 2021). But there are also benefits that will not be so easily forgotten - the chance of the individualization of learning experiences, the opportunity to develop self-directed learning and digital skills, access to learning when it would not otherwise be possible, and the fact that technologies and technological solutions that are widely used by students and are often convenient solutions for other activities have now been introduced as effective ways of learning as well (Bonde et al. 2020, Dhawan 2020, Nolen, Koretsky 2018). Therefore it is likely that technologies will be used in education to a larger extent than before the COVID-19 crisis. Moreover, technology will probably be demanded by students, their parents, and even governments as an alternative form of learning in parallel to face-to-face learning in schools as well as institutions of higher education and further education (Azorín 2020, Balyer, Öz 2018, Nolen, Koretsky 2018). However, the cases in which remote learning can be scientifically justified over faceto-face learning and how it should be organized for the maximum benefit of society are yet to be discerned. To ensure that learning can happen in a remote mode, there is a necessity to strengthen the digital competence of all parties involved (Olesika, Lama, Rubene, 2021; Biezā, 2020; Rubene, 2018; Lee \& Choi, 2017; Davis, 1986), which is an important component of remote learning (Becker et al., 2020, Eustler, 2020, Daniela, Visvizi, 2020), whether it is a synchronous or asynchronous learning process (Cleveland \& Block, 2017, Anderson and Dron, 2011).

\section{Methodology}

To study the digital transformation of education, as a part of CoLife project, an interdisciplinary team was established. During the project, close collaboration between scientific groups and specialists from the related economic sectors was developed - both educators and IT specialists were involved in the research. Educational science researchers from three higher education institutions - the University of Latvia, Rezekne Academy of Technologies, and Riga Stradins University - collaborated in the project, and the IT field was represented by the Institute of Electronics and Computer Science.

The research questions were connected by two education transformation directions related to digitalization processes at all levels of education: the human orientation (Education Law, 1998; European Commission, 2018), and the orientation towards a technology-enhanced environment (Prague Communiqué, 2001; Paris Communiqué, 2018). The research questions were as follows:

1. How did the COVID-19 crisis contribute to the digital transformation of education? 
2. Which of the changes in education caused by the COVID-19 crisis situation should be maintained in the future?

Until the crisis caused by COVID-19 in Latvia, there was no previous experience of remote learning being organized for students of all educational levels to such an extent. When the educational institutions were abruptly closed in March 2020 and remote learning was introduced, much of the decision-making was left to local governments and educational institutions, resulting in diverse and often not very successful measures to ensure further learning. As the remote learning caused by the COVID-19 pandemic continues, there is a growing need to find the trigger points that inhibit successful teaching and learning, adapt learning processes, and clarify the terminology used when addressing remote learning as a new phenomenon of education.

In order to respond to the educational challenges posed by the COVID-19 crisis, the following research tasks were put forward:

- to develop a tool for the functional evaluation of existing digital learning platforms as well as recommendations for the implementation of these platforms in order to provide a technology-enhanced learning process;

- to identify the needs for the digital skill development of educators from preschool level to general and higher education and to develop proposals for the improvement of the digital and pedagogical skills of educators in the context of the COVID-19 crisis;

- to conceptualize recommendations for policy-makers for the digital transformation of education in relation to digitalization and the use of digital solutions at all levels of education (preschool, general education, higher education), thus laying the foundation for establishing and implementing a flexible and student-focused education.

This article focuses on the process and results of the conceptualization of these recommendations, which is put forward as an objective of this research. All other results will be published separately (Daniela, Rubene, Rudofa, 2021).

To fulfill the research objective, it was important to understand the relationship between the theoretical framework and empirical research and society, as well as to indicate different conceptions of this relationship. The consequences of the crisis are forcing education researchers to re-evaluate and re-conceptualize the digital transformation of education and society. Re-conceptualizing the social world means providing a critical view of society, demonstrating that familiar and apparently unremarkable features of everyday life can stimulate diverse questions (Cooper, Meadows, 2016).

To conceptualize the recommendations for policy-makers on the digital transformation of education, we chose the Delphi method. This is 
characterized as a method for structuring group communication processes, so it is effective in allowing a group of individuals as a whole to deal with complex problems. The Delphi method is often termed the 'Delphi technique' because it provides a design for undertaking research which is underpinned by theoretical explanation. This makes it more than just a data collection mechanism (Cohen et al. 2007; Williamson 2002). The Delphi method is often used as a method of systematic interactive prognosing which is based on expert opinion. Assessing the consequences of the COVID-19 crisis and conceptualizing guidelines for future education are complex issues that require the collaboration of experts from multiple fields to solve, so we considered the Delphi method to be appropriate for reaching our aim.

The Delphi method is designed to achieve a consensus between the views of the group members involved, and it usually includes three rounds:

1. The researcher asks participants to respond to a series of questions and statements in writing. This may be done on an individual basis or on a small group basis.

2. The researcher collects the written responses and collates them into clusters of issues and responses (maybe providing some numerical data on the frequency of responses). This analysis is then passed back to the respondents for comment, further discussion, and the identification of issues, responses, and priorities. At this stage, the respondents are presented with a group response (which may reflect similarities or record differences), and the respondents are asked to react to this group response. By adopting this procedure, individuals have the opportunity to agree with the group response (i. e. to move from a possibly small, private, individual disagreement to a general group agreement) or to indicate a more substantial disagreement with the group response.

3. The recirculation of responses has to stop at a group meeting (in our case, a focus group discussion), which is the endpoint of data collection (Cohen et al. 2007).

To reach the planned results of the CoLife project, 8-10 experts took part in each discussion. Among them were educators from preschools (2-3), schools (2-3), and higher education institutions (2-3), as well as school and high school management representatives of both state-funded and privately-funded institutions and a business representative from the education technology field. All experts had experience in the field of remote learning and expressed their views on the digitalization of education, remote learning, and the development of the professional competence of educators. The experts completed three questionnaires (expressing their opinions without interacting) and after that participated in three focus group discussions (expressing their opinions interactively). The experts 
were coded according to the following logic - the letter $\mathrm{P}$ was used for experts from preschools, $\mathrm{S}$ for experts from schools, $\mathrm{H}$ for experts from high schools, and $\mathrm{T}$ for the representative of the education technology field. A number was added to each letter to differentiate between experts; this was done in alphabetical order of their names and according to the date they joined the expert group.

Three surveys were created to gather the views of the experts. Each survey was designed to take around 10-15 minutes of the respondents' time. Approximately a week was given for the experts to fill in each survey. The questionnaires included statements with key terms for the discussions. The first survey consisted of nine questions. The first five questions were definitions of key terms for the discussion; the experts had to use a 3-point Likert scale (agree, partially agree, or disagree) to evaluate each definition. Experts who partially agreed or disagreed were asked to explain their opinion. In the 6 th question, the experts had to arrange five provided categories of platforms and tools for online learning by their importance. The 7th question asked about the importance of the possibility to enhance self-directed learning via a learning platform (Likert scale - very important, important but not critical, not important: learning content is more important). The 8th question asked the experts to evaluate the importance of 10 criteria provided for evaluating online learning necessities (on a 5-point Likert scale from not important to very important). The 9th question asked experts to evaluate the importance of 13 criteria provided for evaluating online learning platforms (on a 5-point Likert scale from not important to very important).

The second survey consisted of four parts. The first part contained five main conclusions from a statewide evaluation of the distance learning process caused by the COVID-19 pandemic in spring 2020; answers from students, their parents, and teachers were taken into consideration. The experts were asked to read these conclusions before filling in the rest of the form. A link to the full dataset was also given. The second part of the survey asked the experts to express their opinions on eight statements about the distance learning process (on a 7-point Likert scale from fully agree to fully disagree). They were asked to briefly comment on the evaluations. In the third part of the survey was an open question, which asked the experts to express their opinion about the possible continued use of remote learning as part of the learning process even after the COVID-19 pandemic and state the main risks and benefits of doing so. The last part of the survey asked the participants to evaluate if, and if so to what extent, remote learning should be used for different student age groups - from preschool to high school - on a scale from $0-100 \%$. They were asked to comment on their choices. 
The third survey consisted of five parts. In the first part, the experts had to choose one main component out of four concerning teachers' and lecturers' digital competency. It was possible to add different components and comment on their choice. The second question asked about the importance of five criteria for organizing digital competence development courses (on a 5-point Likert scale from not important to very important). It was possible to add different criteria and comment on their choice. The third part of the survey asked experts to evaluate the impact that the COVID-19 pandemic-caused distance learning had had on teachers' and lecturers' digital competency; four statements were given (with a 7-point Likert scale from fully disagree to fully agree). It was possible for them to comment on their choice. The fourth part of the survey asked the participants to evaluate teachers' and lecturers' digital competency at that moment; ten statements were given (using a 7-point Likert scale from fully disagree to fully agree). It was possible for them to comment on their choice. The last part of the survey was an open question that asked the experts to share their views on what factors could motivate teachers and lecturers to further develop their digital competency even after the COVID-19 pandemic.

Focus group discussions were organized to reach a consensus. The surveys were analyzed, and the results were then used for discussion purposes. Quotes from the answers were also included in discussion presentations. First, the participants of the discussions were introduced to the research results, their survey responses were analyzed, and then a moderator organized discussions amongst them using both the research results and the survey analysis. All conversations were filmed and transcribed for later analysis and formation of the most important theses about each topic discussed. The discussions took place online; each discussion was 2 hours long, including presentations of the research results and participant survey analyses. As a result of the focus group discussions, the experts reached a consensus on their proposals and recommendations for policy-makers.

The focus groups with experts were organized in Latvian, and all the answers were translated into English by the researchers.

\section{Results}

As mentioned above, the Delphi method was used to conceptualize recommendations for educational policy-makers on three issues: the use of digital learning platforms, blended and remote learning in education at all levels, and developing digital and pedagogical digital competences of educators, emphasizing the consequences of the COVID-19 crisis. The data was analyzed using a hermeneutic design approach (Wernet 2014) for the interpretation of the data obtained from the analysis. 


\section{Expert opinions on the use of digital learning platforms}

Experts pointed out that although there was no ideal learning platform, a common platform was needed, not just for collaborating online but also for nationwide access to digitized learning materials.

P2: "Many of the digital tools currently used for educational purposes were not initially built for this. Having a common digital solution specially designed for education needs could significantly improve the situation." P3: "The sheer amount of accessible digital tools to choose from is an inconvenience for many teachers. Having common digital solutions could relieve this extra burden."

S1: "A lot of resources are spent irrationally, with each learning institution trying to choose from the offered platforms and support educators learning to use them. It would be much more effective to collaborate on learning and using a common platform."

H2: "It is a task for the state to provide a common learning platform that includes not just the tools for learning but also access to digitized learning materials. Having a common digital solution could also ensure the compatibility of the chosen tools, therefore making the sharing and transfer of data easier."

T1: "It is also important to have content customized for cultural background. A common platform with access to such content could promote accessibility."

Some experts, however, were hesitant about choosing a common digital solution for everyone.

S3: "I would not like educators to be forced to use specific digital solutions, especially if they have a good justification for using other digital tools."

T1: "Although a common platform is needed, I do not believe that it would be used by everyone."

One expert pointed out that having a common digital solution would not exclude using other digital solutions if the educator chose so.

S2: "There could still be an option to individualize such a common platform for those who wished it by embedding other digital solutions, for example."

Several experts also expressed their concerns about data safety while using digital solutions for learning.

H1: "I choose not to create digital content. I do not have the confidence that my copyrights will be respected."

H4: "Currently, students have the right not to use Zoom as a communication tool, if they so choose."

An expert from the field of higher education pointed out that although there were clear benefits to having common learning materials for schools, 
this probably did not apply for higher education, since specialization at this educational level gets narrower and there are therefore much fewer common materials that could be used nationwide.

H1: "The needs in higher education are too specific for common content to be relevant. A common technical solution could, however, be useful."

\section{Blended and remote learning in education at all levels}

The survey showed that the experts were cautious when evaluating educational institutions and educators' readiness for the remote learning process; furthermore, they felt less sure about educators' readiness for it.

S3: "Before introducing remote learning outside the pandemic context, we must understand the aim for it."

P5: "It is important to know how the remote learning process will be organized. In our institution we have guidelines for remote learning, containing clear points for what students, their teachers, and parents should be doing. It is not self-evident. "

Most experts who participated in focus group discussions agreed that remote learning was less qualitative than face-to-face learning apart from one, who strongly disagreed with this statement, explaining that if it was well organized it could be as qualitative as learning face-to-face. In the discussion, it was established that social interactions were lacking, especially for those groups who had never had the chance to meet face-to-face. Several experts expressed concern about students' academic honesty while learning remotely. The lack of support and availability of possible solutions were some of the concerns raised. It was also pointed out in the discussion that we should not undervalue the importance of a comfortable learning space and the possibility to socialize offered by educational institutions while learning face-to-face, especially considering that many students do not have suitable conditions for learning and socializing at home.

H1: "If you work remotely from the beginning it's different. You haven't had the chance to meet face-to-face, to talk. This has to be artificially organized online - it doesn't happen on its own."

H4: "Academic honesty and risk evaluation is not a simple task. Educators can't even imagine the ways in which they could be deceived."

P4: "It is possible that school is the only place where positive emotions can be acquired for some students."

One expert agreed that distance learning was contributing to improving students' and educators' digital competencies. The results about self-directed learning skills were not so definitive, although the majority tended to agree that remote learning improves them.

H4: "Students start their studies and have to learn not only the planned content but also using the technologies chosen by educators. Furthermore, 
not all educators use the same tools. This greatly increases the cognitive load for students. This has to be taken into consideration when planning learning."

H1: "Why can't teachers plan the learning framework and let students choose the most suitable forms of learning for themselves? For instance, some students might find it boring to learn from videos and therefore choose other, perhaps face-to-face activities, while others might choose to watch these videos because it helps them learn at their own pace. This would help them take responsibility for their learning."

Approximately $30 \%$ of the experts in the survey were mostly positive about remote learning, $40 \%$ were neutral in their statements, and $30 \%$ were mostly negative. Most experts agreed that remote learning should not be organized for preschool students but can be introduced gradually in schools, starting from the 1st grade.

P3: "It is complicated to organize remote learning in preschool, but not impossible. Students love remote learning in small doses. The amount of remote activities should be increased gradually with students getting older. It helps students grasp that they need the learning, not their teachers." H4: "Remote learning is a problem now, but it could be an opportunity after the pandemic."

\section{Expert opinions on developing digital and pedagogical digital competencies of educators}

In the survey, all experts admitted that participants' age was of importance when planning professional development. 75\% of experts agreed that remote learning caused by the COVID-19 pandemic increased the digital competencies of educators, and 90\% agreed that educators had improved their skills to use digital solutions for communicating with their students remotely and used digital tools better in order to teach theoretical content online. However, only $40 \%$ of experts agreed that educators improved their skills in creating digital learning materials and problem-solving skills connected with digital solutions. Opinions were divided on whether educators promoted student collaboration online, gave and received feedback, with approximately half of the experts mostly agreeing and half mostly disagreeing. $90 \%$ of experts believe that educators see the need to improve their digital skills and that support from IT specialists is needed to successfully digitize learning.

During the focus group discussion, experts pointed out that although there is an interest amongst educators to learn to use digital solutions, many are hesitant because of their lack of experience..

P3: "There is an interest among educators, but many don't have enough skills to successfully use digital solutions yet." 
P1: "It is important to get rid of the fear of using digital solutions. Practical learning with help in using digital tools that are readily required in the learning process might help. Students could learn together with their teachers."

S2: "Teachers need to experience learning activities with digital solutions themselves to be able to successfully implement them in their work."

Experts pointed out that, oftentimes, educators lacked not only access to digital tools and solutions but also resources to create digital learning content - time and necessary support.

H6: "There are many opportunities to digitize the learning content, but no time or support is planned for it."

T1: "It is relevant that teachers have continuous support in using digital solutions. Someone who offers advice in choosing and using digital solutions for certain activities. It is not something each educator can always do on their own, especially considering current workloads among educators." After analyzing and synthesizing the experts' opinions, the recommendations for the institutional and national levels were formed.

\section{National level recommendations:}

- Clarification of technology-enhanced learning terminology, especially the terms related to blended and remote learning.

- National level guidelines for the management of personal data that can be supplemented with institution-specific information.

- An instrument for evaluating the readiness of educational institutions to carry out technology-enhanced learning.

- A common learning platform for educators to reduce fragmentation in the offerings of currently available platforms. It is necessary to publish information on this platform about the digital learning tools offered by the state and developed by private entrepreneurs, as well as to provide self-learning tools in Latvian for teachers to be able to master the offered tools.

- A common learning platform for students with differentiated digital learning materials according to national standards and curricula and integrated digital learning and teaching tools that allow a high level of participatory interactivity to promote self-directed student learning.

- New digital solutions must be sought for by public-private partnerships to fill educational necessities that cannot be met by existing solutions.

- Entirely remote learning is not suitable for students under 12 years of age outside the crisis context because social learning is especially important for students of this age - the need for care, teacher mediation, possible risks for cognitive development, etc. It would therefore be productive to carefully consider the suitability of remote learning for 
specific pupils or groups at this age. However, the gradual implementation of blended learning to a certain extent for students under the age of 12 promotes the development of self-directed learning and digital skills, as well as the personalization of the learning process.

- For students from the age of 12, blended or remote learning is considered to be a more appropriate type of learning, while for students aged 17 and above, the above-mentioned risks are significantly reduced by remote learning. However, from the age of 12, a new group of risks emerges, which are related to the decline of skills in social and relationship building, verbal communication, acceptance of different opinions, recognition of false messages, etc. A separate group of risks is related to the psychological challenges caused by social isolation and loneliness.

- In the process of implementing blended and especially remote learning, special attention should be paid to reducing the risk of early school drop out for students from the age of 12 , which is the most significant risk for this age group.

- Remote education is the "new normal" and must therefore remain part of formal education in the future. However, it is important to distinguish between crisis periods when there are no possible alternatives to remote learning and post-crisis periods in which it should be possible to choose the most appropriate activities to complement face-to-face learning.

- Further research is needed to acquire evidence-based conclusions and a common view on the appropriate proportion of remote learning for students from different age groups.

- Institutional level recommendations:

- To develop an algorithm for remote learning in educational institutions, taking into account the available equipment, the technical readiness of staff and students, the specificities of the age group, the number of contact hours, the social conditions of families, and other relevant factors.

- To provide technical and methodological support staff for educators to implement digitally and pedagogically suitable solutions for teaching and learning, evaluating, gathering, and interpreting data for decision-making and other relevant requirements to provide qualitative remote education.

- To take into account three aspects in the professional development of educators: (1) knowledge related to the various available technologies, their characteristics, and interest in them; (2) knowledge of key theories and concepts of the specific field of training (e. g. natural sciences, mathematics, languages) and their specific research tools; and (3) knowledge of learning theories, i. e. the training process and readiness to support and manage the learning situation and learning process. 
- To acquire and implement technical solutions to ensure monitoring possibility for remote learning, including verifying the originality of study papers and monitoring examinations.

- The OECD report "Impacts of technology use on children. Exploring literature on the brain, cognition and well-being" [35] states that the recommended screen time for school-age children is two hours a day. We encourage schools to work with families so that children use this time for learning purposes. We also call for attention to the fact that not all families can address this problem, and support from professionals is needed.

- Educational institutions and/or parents should be able to choose remote learning to meet the needs of a particular student or group of students (e. g. caused by students' long-term illness or absence or his/her parents' professional activity, home-schooling).

\section{Conclusions}

The COVID-19 crisis has caused rapid changes in educational institutions around the world, creating numerous challenges that require urgent solutions. Ongoing comprehensive remote learning is a solution to the crisis, but the remote learning brought about by this crisis often is not fullfledged remote learning. Face-to-face formats are transferred online without much consideration of the specific nature of remote learning, and there are not enough centralized support systems available for teachers, learners, or their families, who often find themselves trying to correct deficiencies in the available systems.

The large-scale digitalization of education during the COVID-19 crisis has shown that, at such a scale, this process poses a number of significant risks, including differences in access to education caused by the digital divide; differences in student skills and accessible support systems; limited resources accessible to educational institutions and educators for providing a qualitative remote learning process; the readiness of educational institutions and educators to shift towards a student-centered learning process which is at the core of remote learning; the standardization of curricula and technology companies' potential impact on education; and security risks such as breaches of data security, copyright, evaluation, etc. However, there are also undeniable benefits and opportunities that the digitalization of education offers: the chance to individualize learning experiences, the opportunity to develop self-directed learning and digital skills, the provision of access to learning when it would not otherwise be possible, etc.

The challenges caused by this crisis have contributed to the availability of digital resources and the improvement of the digital competencies of 
professionals involved in all levels of education who now have to implement blended and especially remote learning in their practice. There is a growing interest among education professionals in digital content and opportunities to communicate, collaborate, and create a favorable 'learning ecosystem' online. It is agreed that better technological solutions are needed to achieve the required educational goals, but it is even more important to provide professional development and the necessary resources for educators to make appropriate use of existing and new technological solutions. Therefore, we believe that the process of digital transformation in education needs to be continued in order to ensure a modern and efficient learning process at all levels of education in the future.

\section{Acknowledgements}

The development of the article was supported by State Research Program "COVID-19 mitigation" project "Life with COVID-19: Evaluation of overcoming the coronavirus crisis in Latvia and recommendations for societal resilience in the future" No. VPP-COVID-2020/1-0013 (COVIDzive).

\section{References}

Anderson, T., \& Dron, J. (2011) Three generations of distance education pedagogy. The International Review of Research in Open and Distributed Learning, 12(3), 80-97.

Azorín, C. (2020), “Beyond COVID-19 supernova. Is another education coming?” Journal of Professional Capital and Community, 5(3/4), 381-390.

Balyer, A., \& Öz, Ö. (2018). Academicians' views on digital transformation in education. International Online Journal of Education and Teaching (IOJET), 5(4), 809-830.

Becker, S. P., Breaux, R., Cusick, C.N., Dvorsky, M. R., Marsh, N. P., Sciberras, E., Langberg, J. M. (2020) Remote Learning During COVID-19: Examining School Practices, Service Continuation, and Difficulties for Adolescents With and Without Attention-Deficit/Hyperactivity Disorder, Journal of Adolescent Health, 67(6), 769-777, ISSN 1054-139X

Biezā, K. E. (2020) Digital Literacy: Concept and Definition. International Journal of Smart Education and Urban Society, 11(2), 1-15.

Bonde, M., Makransky, G., Wandall, J. Larsen M., Morsing M., Jarmer H., Sommer M. (2014) Improving biotech education through gamified laboratory simulations. Nat Biotechnol, 32, 694-697.

Blundell, R., Costa Dias, M., Joyce, R. and Xu, X. (2020), COVID-19 and Inequalities*. Fiscal Studies, 41, 291-319.

Cleveland, S. \& Block, G. (2017) Toward knowledge technology synchronicity framework for asynchronous environment. International Journal of Knowledge Society Research, 8(4): 23-33.

Cohen, L., Manion, L., Morrison, K. (2007) Research methods in Education. London and New York, Routledge. 
Commission Recommendation (EU) 2018/951 of 22 June 2018 on standards for equality bodies. http://data.europa.eu/eli/reco/2018/951/oj

Cooper, G., Meadows, R. (2016) Conceptualising Social Life. In: (Ed. Gilbert, N., Stoneman, P.) Researching Social Life. Los Angeles, London, New Delhi, Sage, pp. 10-24.

Daniela, L., Rubene, Z., Rudolfa, A. (2021) Parents' Perspectives on Remote Learning in the Pandemic Context. Sustainability 2021, 13, 3640.

Daniela, L., Visvizi, A. (2021) Remote learning as a mode of distance learning, in Distance Learning in Times of Pandemic: Issues, Implications and Best Practice, eds L. Daniela and A. Visvizi, Routledge: London, UK; New York, NY, USA, 2021.

Darling-Hammond, L., Hyler, M. E. (2020) Preparing educators for the time of COVID ... and beyond, European Journal of Teacher Education, 43(4), 457-465.

Davis, F. D. (1986) A technology acceptance model for empirically testing new end-user information systems: theory and results. PhD thesis, MIT Sloan School of Management, Cambridge, MA.

Dhawan, S. (2020). Online Learning: A Panacea in the Time of COVID-19 Crisis. Journal of Educational Technology Systems, 0047239520934018.

Digiuseppe, M., Oostveen, R., Childs, E., Blayone, T., Barber, W. (2017). Are you ready? Assessing Digital Competencies for Online Learning via the General Technology Confidence and Use (GTCU) Instrument. Conference: EdMedia: World Conference on Educational Media and TechnologyAt: Washington, D.C.

Education Law in Latvia (1998), https://likumi.lv/ta/id/50759-izglitibas-likums

Eutsler, L. (2020) Pandemic induced remote learning increases need for mobile gamebased learning to engage learners. Education Tech Research Development.

Harris, A. (2020), "COVID-19 - school leadership in crisis?" Journal of Professional Capital and Community, 5(3/4), 321-326.

Iivari N., Sharma S., Ventä-Olkkonen L. (2020), Digital transformation of everyday life How COVID-19 pandemic transformed the basic education of the young generation and why information management research should care?, International Journal of Information Management, Vol. 55, December 2020, 102183

Impacts of technology use on children. Exploring literature on the brain, cognition and well-being. (2019) OECD. https://www.oecd-ilibrary.org/docserver/8296464e-en.pdf?expires $=1606740727 \& \mathrm{id}=\mathrm{id} \& \mathrm{accna} M e=$ guest $\&$ checksu $M=\mathrm{E} 4 \mathrm{C} 7668[1] 1971 \mathrm{AACB} 302$ AAE6C8CC2CB0F7

Karalis, T. (2020). Planning and evaluation during educational disruption: lessons learned from COVID-19 pandemic for treatment of emergencies in education. European Journal of Education Studies, 7(4), 125-142.

Lee, J. \& Choi, H. (2017) What affects learner's higher-order thinking in technologyenhanced learning environments? The effects of learner factors. Computers \& Education, $115,143-152$.

Nabarro D. \& Atkinson, J. (2020) "Learning to Live with the New Coronavirus: Anticipation, Articulation, Adaptation, and Accountability," COVID-19 Narratives, April 28, 2020, https://www.4sd.info/COVID-19-narratives/learning-to-live-with-the-new-coronavirus

Nolen, S. B., Koretsky, M. D. (2018) "Affordances of Virtual and Physical Laboratory Projects for Instructional Design: Impacts on Student Engagement," in IEEE Transactions on Education, 61(3), 226-233. 
Olesika, A., Lama, G., Rubene, Z. (2021) Conceptualization of Digital Competence, International Journal of Smart Education and Urban Society, 12(2), 46-59.

Reimer, F. M. \& Schleiche, A. (2020). A framework to guide an education response to the COVID-19 Pandemic of 2020. OECD Library. https://www.hm.ee/sites/default/ files/framework_guide_v1_002_harward.pdf

Rubene, Zanda. (2018) Digital Childhood: Some Reflections from the Point of View of Philosophy of Education. In Innovations, Technologies and Research in Education. Newcastle upon Tyne : Cambridge Scholars Publishing, 2018 Chapter Six, p. 64-77. https://www.cambridgescholars.com/product/978-1-5275-0622-0

Tria, J. Z. (2020). The COVID-19 Pandemic through the Lens of Education in the Philippines: The New Normal. International Journal of Pedagogical Development and Lifelong Learning, 1(1), ep2001.

Vial, G. (2019), Understanding digital transformation: A review and a research agenda, The Journal of Strategic Information Systems, 28 (2) 118-144. https://www.sciencedirect. com/science/article/abs/pii/S0963868717302196.

Wernet, A. (2014). Hermeneutics and objective hermeneutics. In U. Flick (Ed.), The SAGE handbook of qualitative data analysis (pp. 234-246). London: SAGE. 